\title{
EFEITOS DE GEADA NO DESENVOLVIMENTO DO FEIJOEIRO EM SUCESSÃO A ESPÉCIES VEGETAIS E ADUBAÇÃO NITROGENADA $\left({ }^{1}\right)$
}

\author{
ROGÉRIO FARINELLI $\left({ }^{*}\right)$; DOMINGOS FORNASIERI FILHO $\left({ }^{2}\right)$; LUCIANO BORDIN $\left({ }^{3}\right)$; \\ FERNANDO GUIDO PENARIOL $\left({ }^{4}\right)$; CLÓVIS ALBERTO VOLPE $\left({ }^{5}\right)$
}

\begin{abstract}
RESUMO
O objetivo deste trabalho foi verificar o efeito de geada no desenvolvimento do feijoeiro em experimentação de cultivo em sucessão a espécies de cobertura e adubação nitrogenada, em delineamento experimental de blocos ao acaso em esquema de parcelas subdivididas, com quatro repetições. As parcelas foram constituídas pelas espécies Sorghum bicolor tipo guinea, Canavalia brasiliensis, Sorghum bicolor, Crotalaria juncea, Pennisetum glaucum e uma testemunha mantida no "limpo", enquanto as subparcelas por doses de nitrogênio em cobertura $\left(0,25,50\right.$ e $\left.75 \mathrm{~kg} \mathrm{ha}^{-1} \mathrm{de} \mathrm{N}\right)$, utilizando-se como fonte a uréia. Menores danos e severidade da geada foram constatados em plantas de feijão cultivadas após as espécies Canavalia brasiliensis e Crotalaria juncea, devido à menor quantidade de massa seca residual em relação à das culturas de gramíneas. Produtividades superiores de grãos de feijoeiro após geada foram obtidas na sucessão com Crotalária juncea e C. brasiliensis e com a aplicação de doses entre 44,5 e $52,0 \mathrm{~kg} \mathrm{ha}^{-1}$ de $\mathrm{N}$, em cobertura.
\end{abstract}

Palavras-chave: Phaseolus vulgaris L., plantio direto, temperatura, doses de nitrogênio, produtividade.

\section{ABSTRACT \\ FRUST EFFECT IN THE DEVELOPMENT OF COMMON BEAN, IN SUCCESSION COVER CROPS AND NITROGEN FERTILIZATION}

The objective this work was verify the effect of frost in development of common bean in experimentation succession cover crops and nitrogen fertilization. The experimental design used was the randomized blocks in split-plot design, with four replications. The plots were represented by species Sorghum bicolor guinea type, Canavalia brasiliensis, Sorghum bicolor, Crotalaria juncea, Pennisetum glaucum and witness maintained "clean"; the sub parcels by doses of nitrogen applied in topdressing $\left(0,25,50\right.$, and $75 \mathrm{~kg} \mathrm{ha}^{-1}$ of $\left.\mathrm{N}\right)$, being used urea as source of $\mathrm{N}$. Less damages and severity of the frost were observed in bean plants grown after the species Canavalia brasiliensis and Crotalaria juncea, due to the least amount of residual dry mass in relation to the grasses crop. Higher yields of common bean after the frost were obtained with Crotalaria juncea and Canavalia brasiliensis and with application of doses between 44.5 and $52.0 \mathrm{~kg} \mathrm{ha}^{-1}$ of $\mathrm{N}$ in topdressing

Key words: Phaseolus vulgaris L, no-tillage, temperature, doses of nitrogen, yield.

( $\left.{ }^{1}\right)$ Recebido para publicação em 11 de julho de 2008 e aceito em 18 de agosto de 2009.

$\left({ }^{2}\right)$ Departamento de Produção Vegetal, Faculdade de Ciências Agrárias e Veterinárias, Universidade Estadual Paulista (UNESP), 14884-000 Jaboticabal (SP). E-mail: rfarinelli@fcav.unesp.br $\left(^{*}\right)$ Autor correspondente; fornasieri@fcav.unesp.br

$\left({ }^{3}\right)$ Departamento de Controle de Qualidade, Sementes Monsoy/Monsanto, 75650-000 Morrinhos (GO). E-mail: luciano.bordin@monsanto.com

$\left({ }^{4}\right)$ Departamento de Fomento e Fiscalização de Produtos Vegetais, Ministério da Agricultura, Pecuária e do Abastecimento, 70043-900 Brasília (DF). E-mail: fernando.penariol@agricultura.gov.br

${ }^{5}$ ) Departamento de Ciências Exatas, Faculdade de Ciências Agrárias e Veterinárias, Universidade Estadual Paulista (UNESP), 14884-000 Jaboticabal (SP). In memoriam. 
Com a possibilidade de semeadura em três épocas distintas, associada ao ciclo de desenvolvimento curto, é viável a inclusão da cultura do feijão em esquema de rotação no sistema de plantio direto, onde seu desenvolvimento muitas vezes pode ser influenciado pelo cultivo antecessor de espécies de cobertura (WUTKE et al., 1998), sendo promovidas alterações químicas e físicas do solo, em função da decomposição dos resíduos vegetais e beneficiados à produtividade de grãos (SILVA et al., 2003).

As espécies de leguminosas, entre elas a Crotalaria juncea, Mucuna aterrima, Cajanus cajan e Canavalia brasiliensis são importantes pela formação de associações simbióticas com bactérias fixadoras de $\mathrm{N}_{2}$, resultando em quantidades expressivas deste nutriente ao sistema solo-planta e contribuição para a nutrição de culturas subsequentes, especificamente o feijoeiro. Já com a utilização de espécies de gramíneas, no caso a Avena strigosa, Pennisetum glaucum e Sorghum bicolor ocorre a imobilização temporária do nitrogênio $(\mathrm{N})$ na massa microbiana, sendo determinada também mais cobertura do solo devido à menor taxa de decomposição e à elevada produção de massa seca (PERIN et al., 2004).

Outro fator a ser questionado está relacionado com a deposição dos resíduos vegetais na superfície do solo, no período de inverno com presença de temperaturas reduzidas e, consequentemente à ocorrência de geadas. De acordo com BRUNINI et al. (1998), a temperatura em que é promovida a formação de geada no feijoeiro está situada em aproximadamente $3{ }^{\circ} \mathrm{C}$, apesar de existir uma variabilidade genotípica de adaptação às condições extremas de temperatura. Além disso, com a permanência de resíduos na superfície do solo, modificam-se a disponibilidade e a dinâmica do $\mathrm{N}$ em plantio direto, e no cultivo de feijoeiro de inverno em condições irrigadas têm sido observados resultados discordantes quanto à adubação nitrogenada, com variações de produtividade com 60 a $180 \mathrm{~kg} \mathrm{ha}^{-1}$ de N em cobertura (CHIDI et al., 2002; CARVALHO et al., 2003; SORATTO et al., 2004).

O trabalho teve como objetivo avaliar o efeito da geada no desenvolvimento do feijoeiro de inverno, cultivado em sucessão a diferentes espécies de cobertura e com aplicação de doses de nitrogênio em cobertura.

O experimento foi desenvolvido em Jaboticabal (SP), localizada a $21^{\circ} 15^{\prime} 22^{\prime \prime} \mathrm{S}$ a $48^{\circ} 18^{\prime} 58^{\prime \prime} \mathrm{W}$ e altitude de $575 \mathrm{~m}$, em Latossolo Vermelho-Escuro eutrófico. O delineamento experimental utilizado foi o de blocos casualizados em esquema de parcelas subdivididas, com quatro repetições, e cujas parcelas foram representadas pelas espécies de cobertura e uma testemunha mantida no "limpo". As subparcelas foram constituídas pela adubação nitrogenada em cobertura $\left(0,25,50\right.$ e $\left.75 \mathrm{~kg} \mathrm{ha}^{-1}\right)$, fonte uréia, com 15 linhas de feijão de $5 \mathrm{~m}$ de comprimento, sendo considerada como área útil as cinco linhas centrais, desprezando-se 0,5 $\mathrm{m}$ de cada extremidade. As doses foram aplicadas após sete dias da ocorrência de geada não prevista e incorporadas em uma lâmina de água de $15 \mathrm{~mm}$.

As parcelas representadas pelo tratamento no "limpo" foram mantidas sem a presença de plantas daninhas com a aplicação de $2,4 \mathrm{~kg} \mathrm{ha}^{-1}$ de glyphosate, na ocasião do surgimento das infestações. As espécies de cobertura, constituídas por sorgo de guiné (Sorghum bicolor tipo guinea), feijão bravo do Ceará (Canavalia brasiliensis), sorgo duplo propósito cv AG2501C (Sorghum bicolor), Crotalaria juncea cv. IAC-KR1 e milheto cv BN-2 (Pennisetum glaucum) foram semeadas a lanço em 10/3/2000, nas quantidades recomendadas de sementes e incorporadas com grade niveladora semifechada. A dessecação foi efetuada aos 70 dias de desenvolvimento, com $2,4 \mathrm{~kg} \mathrm{ha}^{-1}$ de glyphosate e $806 \mathrm{~kg} \mathrm{ha}^{-1}$ de $2,4 \mathrm{D}$ amina, sendo o material manejado com rolo faca.

A massa seca das espécies vegetais foi avaliada após cinco dias de seu manejo, coletandose três subamostras por parcela, com uma armação de ferro de $1,0 \mathrm{~m}^{2}$, sendo acondicionadas em sacos de papel e levadas à estufa de circulação forçada com temperatura de $65{ }^{\circ} \mathrm{C}$. Para a determinação da porcentagem de cobertura do solo utilizou-se uma carta de espacialização com a distribuição percentual das áreas cobertas.

A semeadura do feijão cultivar Pérola foi realizada em $1 .^{\circ} / 6 / 2000$, tanto na sucessão às espécies de cobertura, como também em tratamento mantido no "limpo", utilizando-se 14 sementes por metro, no espaçamento entrelinhas de 0,45 m, empregando-se $250 \mathrm{~kg} \mathrm{ha}{ }^{-1}$ do formulado 2-25-15. Quanto ao atendimento das exigências de água pela cultura, utilizou-se a irrigação por sistema convencional de aspersão, de acordo com a fase fenológica e necessidade hídrica.

Após cinco dias da ocorrência inesperada de geada em $17 / 7 / 2000$, foram realizadas, nas parcelas designadas às espécies de cobertura e no "limpo", a quantificação de plantas de feijão afetadas pelo fenômeno climático, como também estabelecida nota visual de severidade (adaptado de Coplana, 1995), representada por 0 (plantas sem sintomas), 1 (morte parcial da gema apical), 2 (morte parcial da gema apical e plantas com poucas folhas), 3 (morte total da gema apical), 4 (morte total da gema apical e ausência de folhas) e 5 (morte total de plantas). Para estas avaliações foram efetuadas 10 amostragens por parcela em 1,0 metro na cultura do feijão. 
A produtividade de grãos do feijoeiro foi estimada após o arranquio manual das plantas e posterior trilha mecânica, padronizando-se o grau de umidade a $13 \%$. Os resultados foram submetidos à análise de variância e ao teste F; as médias das espécies de cobertura e no "limpo" comparadas pelo teste de Tukey a $5 \%$ de probabilidade, e para os valores das doses de nitrogênio em cobertura, assim como da interação, realizaram-se estudos de regressão polinomial.

A superioridade das espécies de gramíneas refletiu-se no cultivo de sorgo de guiné e sorgo duplo propósito, obtendo-se aproximadamente uma produção de $13.000 \mathrm{~kg} \mathrm{ha}^{-1}$ de massa seca com $85 \%$ de cobertura do solo (Tabela 1), em virtude do vigoroso desenvolvimento vegetativo e adequado perfilhamento.

Contudo, com os valores de massa seca produzida e da taxa de cobertura morta provenientes do cultivo das espécies de gramíneas, foram ocasionados danos indiretos ao feijoeiro quando as plantas estavam com a quarta e quinta folha trifoliolada desenvolvidas. Nestes estádios fenológicos houve grande quantidade de plantas afetadas pela redução brusca de temperatura, sendo atingida temperatura mínima de $2,4{ }^{\circ} \mathrm{C} \mathrm{com}$ $-4,3{ }^{\circ} \mathrm{C}$ na relva, culminado com a formação da geada, diferentemente da testemunha, mantida no "limpo".

A maior porcentagem de plantas danificadas e a maior severidade promovidas pelo fenômeno climático foram correspondentes à sucessão com sorgo de guiné, em seguida ao sorgo duplo propósito e do milheto (Tabela 1), em que o feijoeiro estava com sintomas característicos da geada, sendo visíveis plantas com poucas folhas, ausência de parte aérea e morte de plantas.

Já em sucessão ao feijão bravo do Ceará, crotalária júncea e no "limpo", os danos decorrentes da geada foram menos severos. A cobertura vegetal e o aporte elevado de massa seca das culturas de gramíneas foram impeditivos à troca de calor do solo com o ambiente e com a formação de palhada foi promovida uma diminuição na amplitude térmica do solo, sendo o mesmo verificado nos resultados de SENTELHAS et al. (1995).

Contudo, após a ocorrência da geada e por se tratar de um cultivar de feijão semiprostrado (entre tipos II e III), a formação e emissão de novos ramos e folhas foram promovidas em função da adubação nitrogenada de cobertura, sendo restabelecido seu crescimento e favorecidos ganhos de produtividade.

Os danos mais severos da geada no feijoeiro em sucessão às gramíneas foram correspondentes às produtividades inferiores, sendo necessárias doses mais elevadas de N (Figura 1), indicando nesse caso, a necessidade de quantidades maiores de $\mathrm{N}$ em virtude da velocidade de mineralização de resíduos culturais de maior relação C:N. Em trabalhos com o feijoeiro em sistema plantio direto constatou-se que a máxima produtividade seria alcançada com a aplicação de $76 \mathrm{~kg} \mathrm{ha}^{-1}$ de $\mathrm{N}$ em cobertura (CHIDI et al., 2002), em torno de $140 \mathrm{~kg} \mathrm{ha}^{-1}$ de N (CARVAlHo et al., 2003), ou em doses superiores a $180 \mathrm{~kg} \mathrm{ha}^{-1} \mathrm{de} \mathrm{N}$ (SORATto et al., 2004).

Tabela 1. Produtividade de massa seca e porcentagem de cobertura do solo por espécies vegetais e, porcentagem de plantas de feijão afetadas pela geada e grau de severidade da geada em plantas de feijão em função do cultivo de espécies vegetais antecessoras. Jaboticabal (SP), 2000

\begin{tabular}{lcccc}
\hline Espécies vegetais & Massa seca & Cobertura do solo & Plantas afetadas & Severidade $\left(^{1}\right)$ \\
\hline & $\mathrm{kg} \mathrm{ha}^{-1}$ & & & \\
Sorghum bicolor tipo guinea & $12.814 \mathrm{a}$ & $86,0 \mathrm{a}$ & $98,0 \mathrm{a}$ & $3,75 \mathrm{a}$ \\
Canavalia brasiliensis & $6.275 \mathrm{c}$ & $45,0 \mathrm{~b}$ & $84,2 \mathrm{a}$ & $1,25 \mathrm{~b}$ \\
Sorghum bicolor & $12.686 \mathrm{a}$ & $84,0 \mathrm{a}$ & $90,5 \mathrm{a}$ & $2,75 \mathrm{ab}$ \\
Crotalaria juncea & $6.854 \mathrm{c}$ & $57,0 \mathrm{~b}$ & $82,7 \mathrm{a}$ & $1,25 \mathrm{~b}$ \\
Pennisetum glaucum & $9.579 \mathrm{~b}$ & $83,0 \mathrm{a}$ & $85,6 \mathrm{a}$ & $2,00 \mathrm{ab}$ \\
Testemunha no "limpo" & - & $28,0 \mathrm{c}$ & $57,3 \mathrm{~b}$ & $1,00 \mathrm{~b}$ \\
\hline Teste F & $54,69^{* *}$ & $289,73^{* *}$ & $6,40^{* *}$ & $5,98^{* *}$ \\
CV $(\%)$ & 8,70 & 3,85 & 7,34 & 21,83 \\
\hline
\end{tabular}

Médias seguidas de letras distintas diferem entre si pelo teste de Tukey a $1 \%$ de probabilidade. ${ }^{* *}:$ Significativo a $1 \%$ de probabilidade. $\left({ }^{1}\right)$ Notas de severidade: 0 (plantas sem sintomas); 1 (morte parcial da gema apical); 2 (morte parcial da gema apical e plantas com poucas folhas); 3 (morte total da gema apical); 4 (morte total da gema apical e ausência de folhas) e 5 (morte total de plantas). 


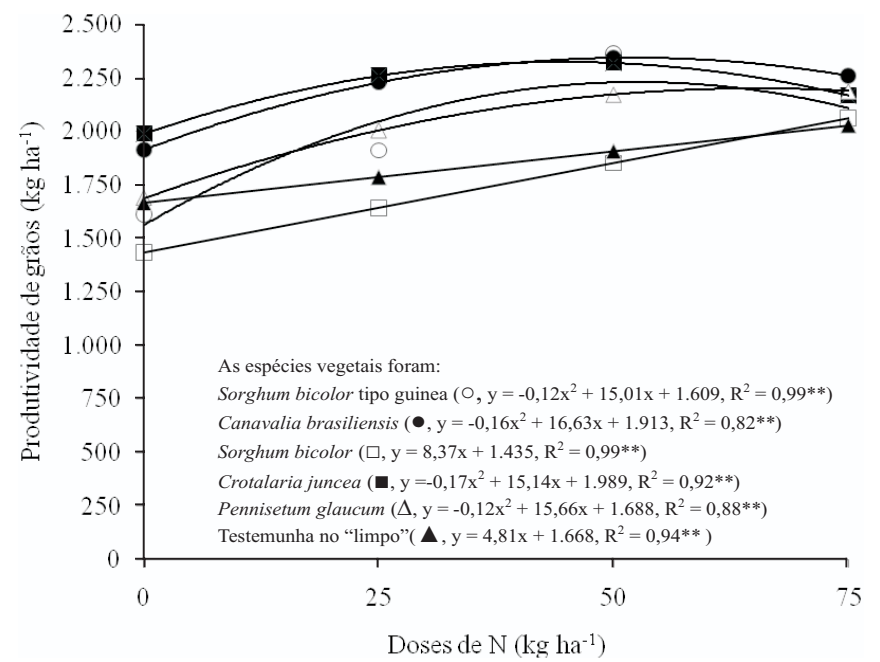

Figura 1. Produtividade de grãos de feijoeiro, após geada, em função de espécies vegetais antecessoras e de adubação nitrogenada em cobertura. Jaboticabal (SP), 2000.

As maiores produtividades de feijão foram obtidas com o cultivo de crotalária júncea $(2.326 \mathrm{~kg}$ $\left.\mathrm{ha}^{-1}\right)$ e feijão bravo do Ceará (2.345 $\left.\mathrm{kg} \mathrm{ha}^{-1}\right)$, com a aplicação de 44,5 e $52,0 \mathrm{~kg} \mathrm{ha}^{-1}$ de $\mathrm{N}$ em cobertura respectivamente (Figura 1), retratando-se a importância das leguminosas na fixação de $\mathrm{N}$ atmosférico e possibilitando-se uma redução nos custos com a adubação nitrogenada (PERIN et al., 2004). Os resultados verificados para estas plantas de cobertura corroboram com WUTKE et al. (1998) e SILVA et al. (2003), nos quais o feijoeiro de inverno cultivado após crotalária júncea teve produtividade de $2.041 \mathrm{e}$ $2.271 \mathrm{~kg} \mathrm{ha}^{-1}$ respectivamente, superando a sucessão com aveia preta, milho e milheto.

Menores danos e severidade da geada são constatados em plantas de feijão cultivadas após as espécies Canavalia brasiliensis e Crotalaria juncea, devido à menor quantidade de massa seca residual em relação à das culturas de gramíneas. Produtividades superiores de grãos de feijoeiro após geada podem ser obtidas na sucessão com crotalária júncea e feijão bravo do Ceará e com a aplicação de doses entre 44,5 e $52,0 \mathrm{~kg} \mathrm{ha}^{-1}$ de $\mathrm{N}$, em cobertura.

\section{REFERÊNCIAS}

BRUNINI, O.; PINTO, H.S.; ZULLO, J. Sistema de aconselhamento agrometeorológico. In: CONGRESSO BRASILEIRODE BIOMETEOROLOGIA, 2., 1998. Gioânia. Anais... Goiânia: Universidade Católica de Goiás, 1998. p.15-37.

CARVALHO, M. A. C.; FURLANI JÚNIOR, E.; ARF, O.; SÁ, M. E.; PAULINO, H. B.; BUZETTI, S. Doses e épocas de aplicação de nitrogênio e teores foliares deste nutriente e de clorofila em feijoeiro. Revista Brasileira de Ciência do Solo, v.27, p.445-450, 2003.
CHIDI, S.N.;SORATTO, R.P.;SILVA, T.R.B.; ARF, O.; SÁ, M.E.; BUZETTI, S. Nitrogênio via foliar e em cobertura em feijoeiro irrigado. Acta Scientiarum, v.24, p.1391-1395, 2002.

COPLANA. Cooperativa dos Plantadores de Cana da Zona de Guariba. Geada. Informe Agrícola, Guariba, n.1, p.1-4, 1995.

PERIN, A.; SANTOS, R.H.S.; URQUIAGA, S.; GUERRA, J,G.M.; CECON,P.R. Produção de fitomassa, acúmulo denutrientes e fixação biológica de nitrogênio por adubos verdes em cultivo isolado e consorciado. Pesquisa Agropecuária Brasileira, v.39, p.35-40, 2004.

SENTELHAS, P.C.; ORTOLANI, A.A.; PEZZOPANE, J.R. Estimativa da temperatura mínima de relva e da diferença de temperatura entre o abrigo e a relva em noites de geada. Revista Brasileira de Agrometeorologia, v.54, p.437-445, 1995.

SILVA, T.R.B.; ARF, O.; SORATTO, R.P. Adubação nitrogenada e resíduos vegetais no desenvolvimento do feijoeiro em sistema de plantio direto. Acta Scientiarum, v.25, p.81-87, 2003.

SORATTO, R.P.; CARVALHO, M.A.C.; ARF, O. Teor de clorofila e produtividade do feijoeiro em razão da adubação nitrogenada. Pesquisa Agropecuária Brasileira, v.39, p.895-901, 2004.

WUTKE, E.B.; FANCELLI, A.L.; PEREIRA, J.C.V.A.; ABROSANO, G.M.B. Rendimento do feijoeiro irrigado em rotação com culturas graníferas e adubos verdes. Bragantia, v.57, p.325-338, 1998. 